\title{
Improving tensile properties of dilute Mg-0.27Al-0.13Ca- 0.21Mn (at.\%) alloy by low temperature high speed extrusion
}

\author{
T. Nakata $^{1)}$, T. Mezaki ${ }^{1)}$, C. Xu ${ }^{1)}$, K. Oh-ishi ${ }^{1)}$, K. Shimizu ${ }^{2)}$, S. Hanaki ${ }^{2)}$, S. Kamado ${ }^{1)}$ \\ 1) Nagaoka University of Technology, 1603-1, Kamitomioka, Nagaoka, 940-2188, Japan \\ 2) Sankyo Tateyama, Inc. Sankyo Material-Company, 8-3, Nagonoe, Imizu, Toyama \\ 934-8515, Japan
}

Contact author: s123055@stn.nagaokaut.ac.jp

Keyword: high-speed extrusion, Mg-Al-Ca-Mn alloy, dynamic recrystallization, texture, tensile properties

\begin{abstract}
As-cast Mg-0.27Al-0.13Ca-0.21Mn (at.\%) alloy was extruded at temperatures from $350{ }^{\circ} \mathrm{C}$ to $500{ }^{\circ} \mathrm{C}$. We examined the microstructural changes during extrusion at different temperatures to clarify dynamic recrystallization mechanisms during extrusion, and also investigated the effect of extrusion temperature on microstructures and mechanical properties of the alloy. High extrusion exit speed of $60 \mathrm{~m} / \mathrm{min}$ was successfully achieved at wide range of temperatures from $350{ }^{\circ} \mathrm{C}$ to $500{ }^{\circ} \mathrm{C}$ even when as-cast dilute Mg-0.27Al-0.13Ca-0.21Mn (at.\%) alloy was used as a billet for the extrusion. The extrusion at low temperature refines
\end{abstract}


grain size and weakens basal texture due to continuous dynamic recrystallization (CDRX) together with double twinning. As a result, the alloy sample extruded at $350{ }^{\circ} \mathrm{C}$ exhibits higher tensile proof stress of $206 \mathrm{MPa}$ and higher tensile ductility of $29 \%$ than T5-treated 6063 aluminum alloy and commercial AZ31 magnesium alloy even in an as-extruded condition. Furthermore, Hall-Petch coefficient for compressive proof stress is 1.8 times larger than that for tensile one, resulting in improvement of yield stress anisotropy (compressive proof stress / tensile yield stress ratio). 


\section{Introduction}

Much attention has been paid to wrought Mg alloys due to their possibility of improving fuel efficiencies by weight reduction of transportation vehicles. But, extrusion speeds of conventional Mg alloys are 1/3 to 2/3 slower than $\mathrm{Al}$ alloys [1]. This leads to high costs for fabricating Mg alloy products by extrusions. Generally, homogenization treatment is utilized to increase the maximum extrusion speed [2]; however, this is regarded as time-consuming process and also requires high-thermal energy, leading to high productive cost. Recently, it is found that, without any homogenization treatment, the maximum extrusion speed of Mg-Al-Zn alloys could be raised by lowering the $\mathrm{Al}$ and $\mathrm{Zn}$ contents [3]; however, as expected, reducing contents of the alloying elements decreases the strengths of the alloys [3], and this makes Mg alloys unsuitable for using as structural components. Precipitates have been used to strengthen Mg alloys [4-6], and it is reported that Mg-Al-Ca alloy system shows significant age-hardening by fine precipitates in spite of their low contents of 0.3 at.\% $\mathrm{Al}$ and 0.3 at.\% Ca [7]. Recent work related to high-speed extrusion of Mg alloy revealed that a dilute Mg-0.27Al-0.13Ca-0.21Mn (at.\%) alloy exhibits sufficient extrudability and moderate age-hardening, resulting in high-strengths [8]. From these results, dilute Mg-Al-Ca-Mn alloys are considered as promising materials for achieving both sufficient extrudablitiy and strengths. On the other hand, little work is conducted about 
dynamic recrystallization (DRX) of dilute Mg alloys [9]; therefore, the relationship between DRX mechanisms and microstructures are unclear in the high-speed extruded dilute $\mathrm{Mg}$ alloys. In this study, we carried out high extrusion exit speed of $60 \mathrm{~m} / \mathrm{min}$ by using as-cast Mg-0.27Al-0.13Ca-0.21Mn (at.\%) alloy and examined the microstructural changes during extrusion at temperatures from $350{ }^{\circ} \mathrm{C}$ to $500{ }^{\circ} \mathrm{C}$. In addition to clarifying DRX mechanisms during extrusion, we investigated the effect of extrusion temperature on microstructures and mechanical properties of the alloy.

\section{Experimental procedure}

An alloy ingot having chemical composition of Mg-0.27 (0.30) Al-0.13 (0.21) Ca-0.21 (0.47) Mn (at.\% (wt.\%)) (hereafter, dilute AXM alloy) and a diameter of $180 \mathrm{~mm}$ was prepared by direct-chill (DC) casting. The microstructure of the as-cast alloy sample was observed by a scanning electron microscope (SEM, JEOL JSM7000F) equipped with an energy dispersive X-ray spectrometry EDS detector and software. Extrusion was carried out using the as-cast alloy sample (no homogenization treatment) having a diameter of $42.9 \mathrm{~mm}$ and a height of $35 \mathrm{~mm}$ at $350,400,450$, and $500{ }^{\circ} \mathrm{C}$ at a die-exit speed of $60 \mathrm{~m} / \mathrm{min}$ with an extrusion ratio of 20. The die used in this study has bearing length of $1.6 \mathrm{~mm}$, bearing angle of $0^{\circ}$, and corner radius of $0.5 \mathrm{~mm}$, and the entrance is a round shape to obtain as-extruded bars with rod shape with $9.6 \mathrm{~mm}$ in diameter and about $500 \mathrm{~mm}$ in length. After extrusion, 
the bars were cooled in an atmosphere. Grain sizes and textures of the as-extruded alloy samples were characterized by an electron backscattered diffraction (EBSD) method using a TSL system on the JSM-7000F. Microstructural evolution during extrusion at $350{ }^{\circ} \mathrm{C}$ and $500{ }^{\circ} \mathrm{C}$ was observed by an optical microscope (OM, VHX2000 KEYENCE) and also by an EBSD method. These observations were conducted by using partially extruded samples (extruded $100 \mathrm{~mm}$ in length) at the positions of $5 \mathrm{~mm}, 10 \mathrm{~mm}$, and $12.5 \mathrm{~mm}$ in front of die-entrance. Transmission electron microscope (TEM) observation was performed using JEM-2100F (JEOL) equipped with an EDS software and a detector, and number densities of second-phase particles in the as-extruded alloy samples were evaluated by using convergent-beam electron diffraction method [10]. Mechanical properties of the as-extruded alloy samples were evaluated by both tensile and compressive tests at room temperature under an initial strain rate of $10^{-3} \mathrm{~s}^{-1}$ using an AUTO GRAPH AG-I (SHIMADZU). The tensile test specimens were $4 \mathrm{~mm}$ in diameter and $22 \mathrm{~mm}$ in gage length, and the compressive test specimens were $9.6 \mathrm{~mm}$ in diameter and $25 \mathrm{~mm}$ in height.

\section{Results and discussion}

\subsection{Microstructure of as-cast sample and extrudability}

Figure 1 shows a SEM image and EDS elemental mapping of the as-cast dilute AXM alloy sample as a billet for extrusion. Only a small amount of compounds consisting of $\mathrm{Al}$ 
and $\mathrm{Ca}, \mathrm{Al}$ and $\mathrm{Mn}$, or $\mathrm{Ca}$ and $\mathrm{Si}$ are observed. Moreover, solute segregation, which is often observed in a commercial as-cast AZ alloy [4], is not observed in the as-cast dilute AXM alloy sample, may be due to the low concentration of alloying elements.

Figure 2 (a) shows the bar surfaces of the dilute AXM alloy samples extruded at the die-exit speed of $60 \mathrm{~m} / \mathrm{min}$ and at temperatures $350{ }^{\circ} \mathrm{C}$ and $500{ }^{\circ} \mathrm{C}$. Both alloy samples show crack-free surfaces despite of the high die-exit speed of $60 \mathrm{~m} / \mathrm{min}$. As shown Figure 2 (b), Atwell et al. [2] performed the direct extrusion into $5.4 \mathrm{~mm}$ round bar using commercial aluminum and magnesium alloys coated by $\mathrm{MoS}_{2}$ based dry solid lubricant, a die with a bearing length of $1 \mathrm{~mm}$, a corner radius of $0.25 \mathrm{~mm}$, and a bearing angle of $0^{\circ}$ with an extrusion ratio of 30, and reported that a commercial as-cast AZ31 alloy sample can be extruded at a die-exit speed of $20 \mathrm{~m} / \mathrm{min}$ at the maximum when the extrusion is performed at $375{ }^{\circ} \mathrm{C}$, and extrusion more than $10 \mathrm{~m} / \mathrm{min}$ of die-exit speed cannot be successfully employed if the extrusion is conducted at $350{ }^{\circ} \mathrm{C}$ or $500{ }^{\circ} \mathrm{C}$. Although a homogenization treatment before extrusions can enhance the maximum extrusion speed of the commercial AZ31 alloy sample, low temperature extrusion at $350{ }^{\circ} \mathrm{C}$ brings about high extrusion load and high temperature extrusion at $500{ }^{\circ} \mathrm{C}$ easily occurs surface cracking if the extrusion speed becomes too high. For these reasons, die-exit speed over $20 \mathrm{~m} / \mathrm{min}$ cannot be applied for the extrusion at $350{ }^{\circ} \mathrm{C}$ and $500{ }^{\circ} \mathrm{C}$ even by using the homogenized commercial AZ31 alloy 
sample [2]. As shown in Figure 2 (c) that represents bar surfaces of AZ31 (Mg-2.7Al-0.3Zn-0.16Mn, at.\%) alloy samples indirectly extruded in our laboratory at $400{ }^{\circ} \mathrm{C}$ at a die-exit speed of $24 \mathrm{~m} / \mathrm{min}$ and $60 \mathrm{~m} / \mathrm{min}$ using an as-cast sample, the maximum extrudable speed of the as-cast AZ31 alloy sample is almost the same in the case of the direct extrusion reported by Atwell et.al. [2] though the extrusion method is different. This result is mainly attributed to coating of $\mathrm{MoS}_{2}$ based dry solid lubricant on the billet surface resulting in lower friction and associated lower heat release for direct extrusion [2]. Therefore, the comparison of the extrudability between this work and the Atwell's work is meaningful for emphasizing the good extrudability of the dilute AXM alloy sample As shown in Figure 2 (a), without any heat-treatment before the extrusion, extrusion at high die-exit speed of $60 \mathrm{~m} / \mathrm{min}$ is successfully achieved at both low temperature of $350{ }^{\circ} \mathrm{C}$ and high temperature of $500{ }^{\circ} \mathrm{C}$ indicating the superior extrudability of the as-cast dilute AXM alloy sample. Moreover, the extrudability of the as-cast dilute AXM alloy sample is comparable to that of a homogenized $6063 \mathrm{Al}$ alloy which has best extrudability among $\mathrm{Al}$ alloys. This good extrudability of the as-cast dilute AXM alloy sample may be due to the small amount of compounds and little solute segregation even in the as-cast state (Figure 1).

\subsection{Effect of extrusion temperature on grain sizes, textures, and second-phase particles}

Figure 3 (a) shows inverse pole figure (IPF) maps and (0001) pole figures on the 
central sections parallel to the extrusion direction of the dilute AXM alloy samples extruded at different temperatures, and Figure 3 (b) summarizes the effect of extrusion temperature on grain size, Schmid factor for basal slip when an applied tensile load is parallel to the extrusion direction, and shear factor for tensile twinning (meaning Schmid factor for tensile twinning) when an applied compressive load is parallel to the extrusion direction. The grain size is effectively refined by the extrusion at lower temperatures; fine recrystallized grains about $10 \mu \mathrm{m}$ is obtained by the extrusion at $350{ }^{\circ} \mathrm{C}$. The basal poles of the alloy sample extruded at $350^{\circ} \mathrm{C}$ are about $40^{\circ}$ away from the transverse direction, while the basal poles of the alloy sample extruded at $500{ }^{\circ} \mathrm{C}$ are tilted at about $30^{\circ}$ from the transverse direction at the maximum suggesting that the texture intensity becomes weaker with decreasing the extrusion temperature. The texture weakening is also can be seen from the changes of the Schmid factor for basal slip, the Schmid factors for basal slip of the extruded alloy samples increase with decreasing the extrusion temperature; the Schmid factors for basal slip of the alloy sample extruded at $350{ }^{\circ} \mathrm{C}$ is 0.22 , while that of the alloy sample extruded at $500{ }^{\circ} \mathrm{C}$ is 0.18 . Hence, it can be said that the basal texture tends to be weakened by extrusion at low temperature. The shear factor for tensile twinning is larger than the Schmid factor for basal slip, and shows the contrary temperature dependence to the Schmid factor for basal slip. However, the changes in the shear factors with decreasing the extrusion temperature are very 
small.

To investigate why the extrusion at low temperature weakens the basal texture, we observed microstructure evolutions during the extrusion at $350{ }^{\circ} \mathrm{C}$ and $500{ }^{\circ} \mathrm{C}$. Figure 4 (a) shows $\mathrm{OM}$ images at positions of $5 \mathrm{~mm}, 10 \mathrm{~mm}$, and $12.5 \mathrm{~mm}$ in front of the die-entrance of the alloy sample partially extruded at $350{ }^{\circ} \mathrm{C}$. Thin deformation bands are observed at an initial stage of the extrusion (at $12.5 \mathrm{~mm}$ in front of the die-entrance) and fraction of these bands are increased with progress of the extrusion. Figure 4 (b) shows OM images at positions of $5 \mathrm{~mm}, 10 \mathrm{~mm}$, and $12.5 \mathrm{~mm}$ in front of the die-entrance of the alloy sample partially extruded at $500{ }^{\circ} \mathrm{C}$. The thin deformation bands observed in the alloy sample partially extruded at $350{ }^{\circ} \mathrm{C}$ are not observed in the case of the extrusion at $500{ }^{\circ} \mathrm{C}$. On the contrary, initial grain boundaries bulge at the initial stage of the extrusion (at $12.5 \mathrm{~mm}$ in front of the die-entrance), and recrystallized grains tend to be formed at the initial grain boundaries. Figure 5 (a) shows the IPF maps at positions of $10 \mathrm{~mm}$ and $12.5 \mathrm{~mm}$ in front of die-entrance of the alloy sample partially extruded at $350{ }^{\circ} \mathrm{C}$. The basal planes of the thin deformation bands, which are also observed in the OM images (Figure 4 (a)), are tilted at about $37^{\circ}$ or $30^{\circ}$ to the basal plane of the Mg-matrix (at $12.5 \mathrm{~mm}$ in front of the die-entrance), suggesting that these bands are formed by occurrences of $\{10 \overline{1} 1\}-\{10 \overline{1} 2\}$ double twinnings [11, 12], and these double twinning areas are divided by low-angle 
boundaries. At $10 \mathrm{~mm}$ in front of the die-entrance, recrystallized grains are observed in the double twinning areas, implying that these grains are formed by continuous DRX (CDRX) during the extrusion at $350{ }^{\circ} \mathrm{C}$ [11]. Figure 5 (b) shows the IPF maps at positions of $10 \mathrm{~mm}$ and $12.5 \mathrm{~mm}$ in front of the die-entrance of the alloy sample partially extruded at $500{ }^{\circ} \mathrm{C}$. At the initial stage of the extrusion (at $12.5 \mathrm{~mm}$ in front of the die-entrance), some grain boundaries bulge as indicated by black arrows and some new recrystallized grains are formed near initial grain boundaries as emphasized by dotted circles. At the next stage of the extrusion (at $10 \mathrm{~mm}$ in front of the die-entrance), more new recrystallized grains are nucleated at the initial grain boundaries as highlighted by dotted circles, and these recrystallized grains become larger than the grains at $12.5 \mathrm{~mm}$ in front of the die-entrance. Generally, discontinuous DRX (DDRX) grains are developed from initial grain boundaries, and the DDRX grains start growing [13]. Hence, the DDRX near the initial grain boundaries is operative during the extrusion at $500{ }^{\circ} \mathrm{C}$. Although coarse tensile twinning is also observed at $10 \mathrm{~mm}$ in front of the die-entrance (Figure 5 (b)), new recrystallized grains are not formed in the twinnings unlike the extrusion at $350{ }^{\circ} \mathrm{C}$. From these reasons, it can be said that main DRX mechanism during the extrusion at $500{ }^{\circ} \mathrm{C}$ is DDRX near the initial grain boundaries. It is reported that the DRXed grains nucleated in shear bands show weak basal texture, while the DRXed grains nucleated by grain boundary bulges exhibit strong basal texture [14, 15]. 
As mentioned in this section, new recrystallized grains during the extrusion at $350{ }^{\circ} \mathrm{C}$ are

nucleated by CDRX due to formation of shear bands (double twinnings), while the new DDRX grains are mainly formed near the initial grain boundaries during the extrusion at $500{ }^{\circ} \mathrm{C}$. From these facts, the changes in basal textures of the dilute AXM alloy samples extruded at different temperatures are attributed to the DRX mechanism.

Figure 6 (a) shows the STEM image and STEM-EDS elemental mapping of the dilute AXM alloy samples extruded at $400{ }^{\circ} \mathrm{C}$. Fine second-phase particles distributed within the matrix are composed of $\mathrm{Al}$ and $\mathrm{Mn}$ as reported in other literatures [4, 16]. Figure 6 (b) shows STEM images of the dilute AXM alloy samples extruded at $350{ }^{\circ} \mathrm{C}$ and $500{ }^{\circ} \mathrm{C}$. Fine second-phase particles with average diameter of about $15 \mathrm{~nm}$ are observed in the alloy sample extruded at $350{ }^{\circ} \mathrm{C}$, while the extrusion at $500{ }^{\circ} \mathrm{C}$ forms relatively large second-phase particles of about $39 \mathrm{~nm}$ in average diameter. The number density of these particles in the alloy sample extruded at $350{ }^{\circ} \mathrm{C}$ is $4.9 \times 10^{20} \mathrm{~m}^{-3}$ while that of the alloy sample extruded at $500{ }^{\circ} \mathrm{C}$ is only $8.5 \times 10^{19} \mathrm{~m}^{-3}$.

\subsection{Effect of extrusion temperature on mechanical properties}

Figure 7 (a) shows tensile stress-strain curves of the dilute AXM alloy samples extruded at different temperatures. Both tensile strengths and $0.2 \%$ tensile proof stresses (hereafter, TPS) are increased with decreasing the extrusion temperature; the alloy sample 
extruded at $350{ }^{\circ} \mathrm{C}$ exhibits the highest TPS of $206 \mathrm{MPa}$ while the alloy sample extruded at $500{ }^{\circ} \mathrm{C}$ shows the lowest TPS of $177 \mathrm{MPa}$. Low temperature extrusion also enhances the tensile ductility; the alloy sample extruded at $350{ }^{\circ} \mathrm{C}$ exhibits the highest tensile ductility of $29 \%$. This high tensile ductility is may be due to the fine grain size and weak basal texture [17-19] as mentioned in section 3.2. Figure 7 (b) summarizes the TPS and tensile ductilities of the dilute AXM alloy samples, conventional AZ31 alloy samples extruded at a low extrusion speed of $2.5 \mathrm{~m} / \mathrm{min}$ and a high extrusion speed of $20 \mathrm{~m} / \mathrm{min}$ [20], recently developed dilute Mg-Al-Zn-Mn (hereafter, AZ) alloy samples extruded at a high speed of 30 $\mathrm{m} / \mathrm{min}$ [21], and easily extrudable 6xxx Al alloy samples designed for extrusion products [22]. Note that the conventional AZ31 alloy sample extruded at the high speed of $20 \mathrm{~m} / \mathrm{min}$ shows lower TPS and tensile ductility than those of the alloy sample extruded at the low speed of $2.5 \mathrm{~m} / \mathrm{min}$ because the extrusion at high speed coarsens grain sizes of Mg alloys [20, 21]. The dilute AXM alloy samples exhibit higher TPS and better tensile ductilities compared to the conventional AZ31 alloy samples and the recently developed dilute AZ alloy samples despite of the higher extrusion speed of $60 \mathrm{~m} / \mathrm{min}$, and also show higher TPS than that of T4-treated 6xxx Al alloy samples. In addition, without any aging treatment, the TPS of the dilute AXM alloy samples exceed the T5-treated $6063 \mathrm{Al}$ alloy sample. Furthermore, the dilute AXM alloy sample extruded at $350{ }^{\circ} \mathrm{C}$ exhibits comparable TPS as the T6-treated $6063 \mathrm{Al}$ alloy 
sample in spite of its much higher tensile ductility of $29 \%$. Although the TPS of the T6-treated $6061 \mathrm{Al}$ alloy sample and T5-treated 6005 alloy sample are higher than that of the dilute AXM alloy samples, the tensile ductilities of the dilute AXM alloy samples are higher than those of the both $\mathrm{Al}$ alloy samples. Figure 7 (c) shows compressive stress-strain curves of the dilute AXM alloy samples extruded at different temperatures. The $0.2 \%$ compressive proof stress (hereafter, CPS) is improved by the low temperature extrusion as well as the TPS (Figure 7 (a)), while change in the compressive ductility is little for all the extruded conditions. In spite of convex stress-strain curves in tension, the compression stress-strain curves show concave shape in all the extruded alloy samples. This may be due to the difference of deformation mechanism for tension and compression [23]. Unlike slip dominated flows in tension, twinning becomes dominant mechanism at an initial stage of compression [23-26] when the applied compressive load is parallel to the extrusion direction. The twinning during compression introduces additional barriers to dislocation movement [27], and $\{10 \overline{1} 2\}$ twinning in Mg reorients the lattice to "hard” crystallographic orientations [25]. Then, transformation of dislocation passing through the twining front induces high hardening rates within the twin interiors [23]. Therefore, the compression curves show concave shape unlike the tension curves.

Generally, proof stresses of metals are increased with decreasing grain sizes, and 
represented by following equation [28, 29]:

$$
\sigma \mathrm{PS}=\sigma_{0}+\mathrm{k}_{\mathrm{y}} \cdot \mathrm{d}^{-1 / 2}(1)
$$

where $\sigma_{\mathrm{PS}}$ is the proof stress, $\sigma_{0}$ is the friction stress for dislocation movement, $\mathrm{k}_{\mathrm{y}}$ is the Hall-Petch coefficient, and d is the grain size. The TPS and CPS of the extruded dilute AXM alloy samples obtained in this study are plotted as a function of the inverse square root of the grain size $\left(\mathrm{d}^{-1 / 2}\right)$ in Figure 8 (a). Both TPS and CPS are correlated well with the $\mathrm{d}^{-1 / 2}$, and enhanced by grain refining. However, the CPS shows stronger dependence on grain size than the TPS. Similar tendency is also reported in extruded AZ31 alloy samples; Hall-Petch coefficient of the CPS becomes higher than that of the TPS [4, 23]. Dominant deformation mechanisms at initial stage of tensile and compressive tests along the extrusion direction are basal or prismatic slip [24, 25] and $\{10 \overline{1} 2\}<10 \overline{1} 1>$ tensile twinning as expected from Figure 3 (b) [23, 26], respectively, and many metals such as $\mathrm{Fe}, \mathrm{Cu}, \mathrm{Zr}$, and also Mg show larger grain size dependencies of twinning stress than slip stress [30, 31]. Considering these results, it is essential that the CPS has the higher Hall-Petch coefficient than the TPS as shown in Figure 8 (a).

On the other hand, the proof stress is also influenced by fine precipitates, and fine Al-Mn particles are observed as shown in Figure 6 (a) and (b). Therefore, we should consider the effect of these particles on the TPS and CPS. An increase in TPS, $\Delta \sigma_{\text {TPS }}$, due to fine 
precipitates can be estimated by [4, 32]:

$$
\Delta \sigma_{\mathrm{TPS}}=\mathrm{M} \mathrm{G} \mathrm{b} /\left\{2 \lambda \pi(1-v)^{1 / 2}\right\} \cdot \ln \left(\mathrm{d}_{\mathrm{p}} / \mathrm{b}\right)(2)
$$

where $M$ is the inverse of Schmid factor, $G$ is the shear modulus (=15 GPa [4]), $b$ is the magnitude of burgers vector ( $=0.32 \mathrm{~nm}[4]), \lambda$ is the mean center-to-center spacing between particles, $v$ is the Poission's ratio $(=0.29[4]), d_{p}$ is the diameter of precipitates. Here, the mean center-to-center spacing between particles, $\lambda$, is given as follows [33]:

$$
\lambda=\mathrm{d}_{\mathrm{p}} / 2 \cdot\left(3 \pi / 2 \mathrm{~V}_{\mathrm{f}}\right)^{1 / 2}(3)
$$

where $V_{f}$ is the volume fraction of precipitates. Proof stresses of Mg alloys are often related to (0002) basal pole intensity [31, 34]; therefore, average Schmid factor for basal slip is used to calculate the $\Delta \sigma_{\mathrm{TPS}}$. Table 1 summarizes the related factors for $\Delta \sigma_{\mathrm{TPS}}$ and resulting $\Delta \sigma_{\mathrm{TPS}}$ for the dilute AXM alloy samples extruded at $350{ }^{\circ} \mathrm{C}$ and $500{ }^{\circ} \mathrm{C}$. There is little difference between the alloy samples extruded at $350{ }^{\circ} \mathrm{C}$ and $500{ }^{\circ} \mathrm{C}$ suggesting that the differences of the TPS of the alloy samples in this study are not the effect of second-phase particles. It is reported that strengths of Mg alloys could be effectively enhanced when fine precipitates with high number density are distributed $[35,36]$. Although the alloy sample extruded at $350{ }^{\circ} \mathrm{C}$ has higher number density of second-phase particles with finer size than that of the alloy sample extruded at $500{ }^{\circ} \mathrm{C}$, the $\Delta \sigma_{\text {TPS }}$ of both samples are almost the same. This is considered to be the contribution of stronger basal texture (meaning high value of the inverse of Schmid 
factor represented by $\mathrm{M}$ in Table 1). According to the equation (2), the $\Delta \sigma_{\text {TPS }}$ becomes high if the alloy sample has strong basal texture (low Schmid factor for basal slip) ; therefore, the $\Delta \sigma_{\text {TPS }}$ of both alloy samples are not significantly changed in spite of the differences of number density and size of the second-phase particles. In contrast to the TPS, the small volume fraction of these second-phase particles observed in this study cannot prevent $\{10 \overline{2}\}$ $<10 \overline{1} 1>$ tensile twinning during compression test $[4,5]$; therefore, the CPS of the dilute AXM alloy samples are not improved by the fine precipitates. For these reasons, the improvements of TPS and CPS by lower temperature extrusions are due to grain refining.

In Figure 8 (b), the tensile and compressive yield anisotropies (CPS / TPS) of the dilute AXM alloy samples are plotted as a function of the inverse square root of the grain size $\left(\mathrm{d}^{-1 / 2}\right)$, and it seems that the finer grain size is favorable for eliminating the anisotropy; the alloy sample extruded at $350^{\circ} \mathrm{C}$ shows the lowest yield anisotropy (highest CPS / TPS) in all the alloy samples. The yield anisotropy is often observed in Mg alloys especially after wrought process due to formation of strong basal texture and can be eliminated by grain refining [31, 37]. The extrusion at lower temperature effectively refines the grain size of the alloy samples in this study; therefore, the dilute AXM alloy sample extruded at $350{ }^{\circ} \mathrm{C}$ shows the highest CPS / TPS.

\section{Conclusions}


The dilute AXM alloy sample is successfully extruded at high die-exit speed of 60 $\mathrm{m} / \mathrm{min}$ at wide range of extrusion temperatures from $350{ }^{\circ} \mathrm{C}$ to $500{ }^{\circ} \mathrm{C}$ without any homogenization treatment before extrusion. The as-extruded dilute AXM alloy samples show better tensile properties than those of the commercial AZ31 and dilute AZ alloys. Furthermore, without any aging treatment, the dilute AXM alloy samples exhibit higher tensile properties than the T5-treated $6063 \mathrm{Al}$ alloy. Especially, the dilute AXM alloy sample extruded at lowest temperature of $350{ }^{\circ} \mathrm{C}$ shows comparable tensile proof stress of $206 \mathrm{MPa}$ and much higher tensile ductility of $29 \%$ as compared to the T6-treated $6063 \mathrm{Al}$ alloy. These attractive tensile properties of the dilute AXM alloy sample extruded at $350{ }^{\circ} \mathrm{C}$ are attributed to the fine grains with weak basal texture formed by CDRX with shear bands (double twinning). In addition to the development of high-speed extrudable $\mathrm{Mg}$ alloy with high strengths and high ductility, we have revealed the strengthening mechanism for high-speed extruded Mg alloys. The dilute AXM alloy samples form finer grain size with decreasing the extrusion temperature leading to high TPS, CPS. Moreover, it is found that the fine grain size is effective for eliminating the tension and compressive yield anisotropy of the high-speed extruded alloy samples. 


\section{Acknowledgement}

This work was supported by JSPS KAKENHI Grant Number 25249101 and JST, Advanced

Low Carbon Technology Research and Development Program (ALCA), 12102886. 


\section{References}

[1] F.E. Katrak, J.C. Agarwal, F.C. Brown, M. Loreth, D.L. Chin, Alternative ways to fabricate magnesium products, Magnesium Technology 2000, Eds by H.I. Kaplan, J.N. Hryn, B.B. Clow, The Minerals \& Materials Society (TMS), 2000, 351-354.

[2] D.L. Atwell, M.R. Barnett, Extrusion limits of magnesium alloys, Metall. Mater. Trans. A, 38 (2007) 3032-3041.

[3] C. Davis, M. Barnett, Expanding the extrusion limits of wrought magnesium alloys, J. Miner. Met. Mater. Soc. (JOM), 56 (Nov 2004) 22-24.

[4] N. Stanford, D. Atwell, The effect of Mn-rich precipitates on the strength of AZ31 extrudates, Metall. Mater. Trans. A, 44 (2013) 4830-4843.

[5] J.D. Robson, N. Stanford, M.R. Barnett, Effect of precipitates on slip and twinning in magnesium alloys, Acta Mater., 59 (2011) 1945-1956.

[6] N. Stanford, M.R. Barnett, Effect of particles on the formation of deformation twins in a magnesium-based alloy, Mater. Sci. Eng. A, 516 (2009) 226-234.

[7] J. Jayaraj, C.L. Mendis, T. Ohkubo, K. Oh-ishi, K. Hono, Enhanced precipitation hardening of Mg-Ca alloy by Al addition, Scripta Mater., 63 (2010) 831-834.

[8] T. Nakata, T. Mezaki, R. Ajima, C. Xu, K. Oh-ishi, K. Shimizu, S. Hanaki, T.T. Sasaki, K. Hono, S. Kamado, High-speed extrusion of heat-treatable Mg-Al-Ca-Mn alloy, Scripta Mater., 
101 (2015) 28-31.

[9] J. Su, S. Kaboli, A.S.H. Kabir, I.H. Jung, S. Yue, Effect of dynamic precipitation and twinning on dynamic recrystallization of micro-alloyed Mg-Al-Ca alloys, Mater. Sci. Eng. A, 587 (2013) 27-35.

[10] T. Konno, Principles of TEM image formation (II), Microns., 43 (2008) 212-218.

[11] E. Martin, L. Capolungo, L. Jiang, J.J. Jonas, Variant selection during secondary twinning in Mg-3\%Al, Acta Mater., 58 (2010) 3970-3983.

[12] S.W. Xu, S. Kamado, N. Matsumoto, T. Homma, Y. Kojima, Recrystallization mechanism of as-cast AZ91 magnesium alloy during hot compressive deformation, Mater. Sci. Eng. A, 527 (2009) 52-60.

[13] F.J. Humphreys, M. Hatherly, Recrystallization and related annealing phenomena second edition, United Kingdam, UK: Elsevier Society, (2004), 427-429.

[14] M.R. Barnett, A. Sullivan, N. Stanford, N. Ross, A. Beer, Texture selection mechanism in uniaxially extruded magnesium alloys, Scripta Mater. 63 (2010) 721-724.

[15] A. Sadeghi, M. Hoseini, M. Pekguleryuz, Effect of Sr addition on texture evolution of Mg-3Al-1Zn (AZ31) alloy during extrusion, Mater. Sci. Eng. A, 528 (2011) 3096-3104.

[16] S.W. Xu, K. Oh-ishi, S. Kamado, F. Uchida, T. Homma, K. Hono, High-strength extruded Mg-Al-Ca-Mn alloy, Scripta Mater., 65 (2011) 269-272. 
[17] J. Koike, T. Miyamura, Microscopic mechanisms of plastic deformation in polycrystalline magnesium alloys, J. Inst. Light Met., 54 (2004) 460-464.

[18] N. Stanford, M.R. Barnett, The origin of “rare earth" texture development in extruded Mg-based alloys and its effect on tensile ductility, Mater. Sci. Eng. A, 496 (2008) 399-408.

[19] S. Sandlobes, S. Zaefferer, I. Schestakow, S. Yi, R.G. Martinez, On the role of non-basal deformation mechanism for the ductility of Mg and Mg-Y alloys, Acta Mater., 59 (2011) 429-439.

[20] T. Murai, S. Matsuoka, S. Miyamoto, Y. Oki, S. Nagao, H. Sano, Effects of zinc and manganese contents on extrudability of Mg-Al-Zn alloys, J. Jpn. Inst. Light Met., 53 (2003) $27-31$.

[21] T. Murai, Extrusion of magnesium alloy, J. Jpn. Inst. Light Met., 54 (2001) 472-477.

[22] ASM International Handbook Committee, Metals Handbook Vol.2 $10^{\text {th }}$ edition, (1990) 100-103.

[23] M.R. Barnett, Z. Keshavarz, A.G. Beer, D. Atwell, Influence of grain size on the compressive deformation of wrought Mg-3Al-1Zn, Acta Mater., 52 (2004) 5093-5103.

[24] Y. Wang, H. Choo, Influence of texture on Hall-Petch relationships in an Mg alloy, Acta Mater., 81 (2014) 83-97.

[25] S.R. Agnew, D.W. Brown, C.N. Tome, Validating a polycrystal model for the 
elastoplastic response of magnesium alloy AZ31 using in situ neutron diffraction, Acta Mater., 54 (2006) 4841-4852.

[26] M.R. Barnett, Twinning and the ductility of magnesium alloys: Part I “Tension” twins, Mater. Sci. Eng. A, 464 (2007) 1-7.

[27] I. Karaman, H. Sehitoglu, A.J. Beaudoin, Y.I. Chumlyakov, H.J. Maier, C.N. Tome, Modeling the deformation behavior of Hadfield steel single and polycrystals due to twinning and slip, Acta Mater., 48 (2000) 2031-47.

[28] G. Sambasivam, Y.V.R.K. Prasad, Grain boundary strengthening in strongly textured magnesium produced by hot rolling, Metall. Trans. A, 13 (1982) 2219-2226.

[29] R.W. Armstrong, Theory of the tensile ductile-brittle behavior of polycrystalline h.c.p materials with application to beryllium, Acta Metall., 16 (1968) 347-355.

[30] M.A. Meyers, O. Vohringer, V.A. Lubarda, The onset of twinning in metals: a constitutive description, Acta Mater., 49 (2001) 4025-4039.

[31] J.T. Wang, D.L. Yin, J.Q. Liu, J. Tao, Y.L. Su, X. Zhao, Effect of grain size on mechanical property of Mg-3Al-1Zn alloy, Scripta Mater., 59 (2008) 63-66.

[32] J.F. Nie, Effects of precipitate shape and orientation on dispersion strengthening in magnesium alloys, Scripta Mater., 48 (2003) 1009-1015.

[33] G.L. Roy, J.D. Embury, G. Edward, M.F. Ashby, A model of ductile fracture based on the 
nucleation and growth of voids, Acta Metall., 29 (1981) 1509-1522.

[34] H. Wang, P.D. Wu, M.A. Gharghouri, Effect of basal texture on mechanical behavior of magnesium alloy AZ31B sheet, Mater. Sci. Eng. A, 527 (2010) 3588-3594.

[35] F.R. Elsayed, T.T. Sasaki, C.L. Mendis, T. Ohkubo, K. Hono, Significant enhancement of the age-hardening response in Mg-10Sn-3Al-1Zn alloy by Na microalloying, Scripta Mater., 68 (2013) 797-800.

[36] F.R. Elsayed, T.T. Sasaki, C.L. Mendis, T. Ohkubo, K. Hono, Compositional optimization of Mg-Sn-Al alloys for hinder age hardening response, Mater. Sci. Eng. A, 566 (2013) 22-29.

[37] M.R. Barnett, C.H.J. Davies, X. Ma, An analytical constitutive law for twinning dominated flow in magnesium, Scripta Mater., 52 (2005) 623-632. 
High-speed extrusion

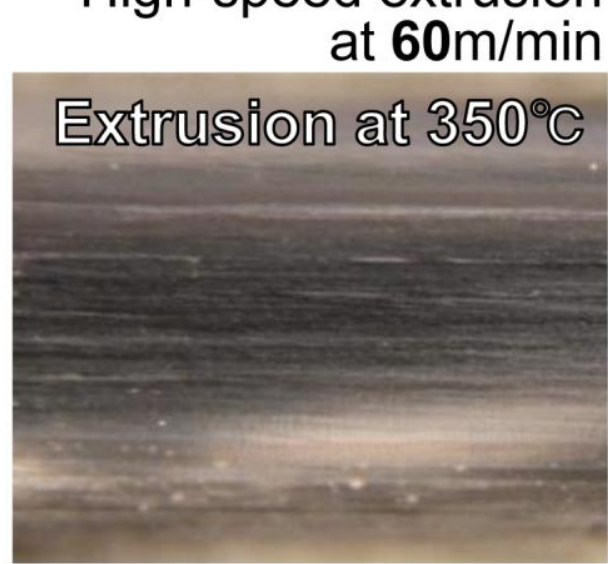

Extrusion at 500C

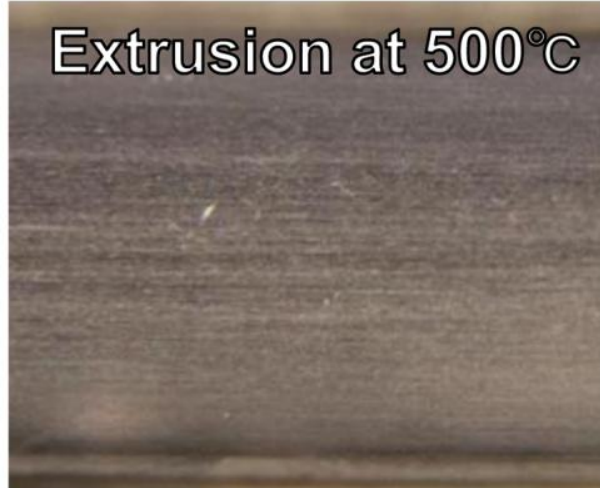

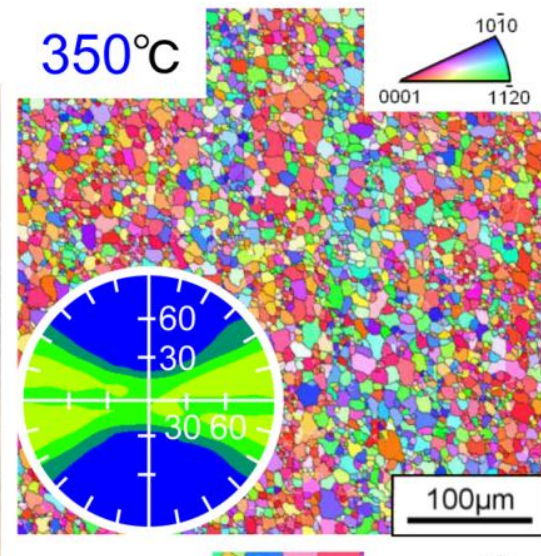

$500^{\circ} \mathrm{C}$

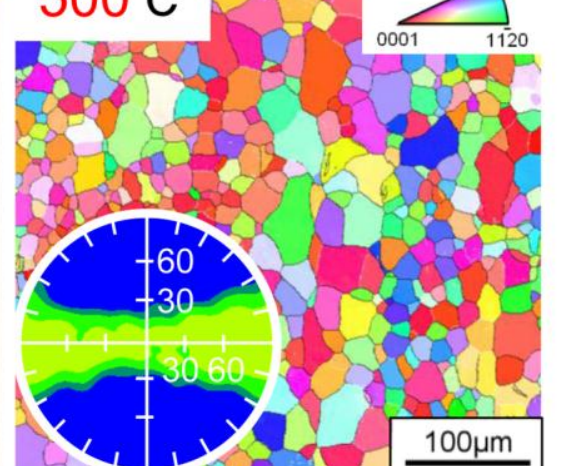

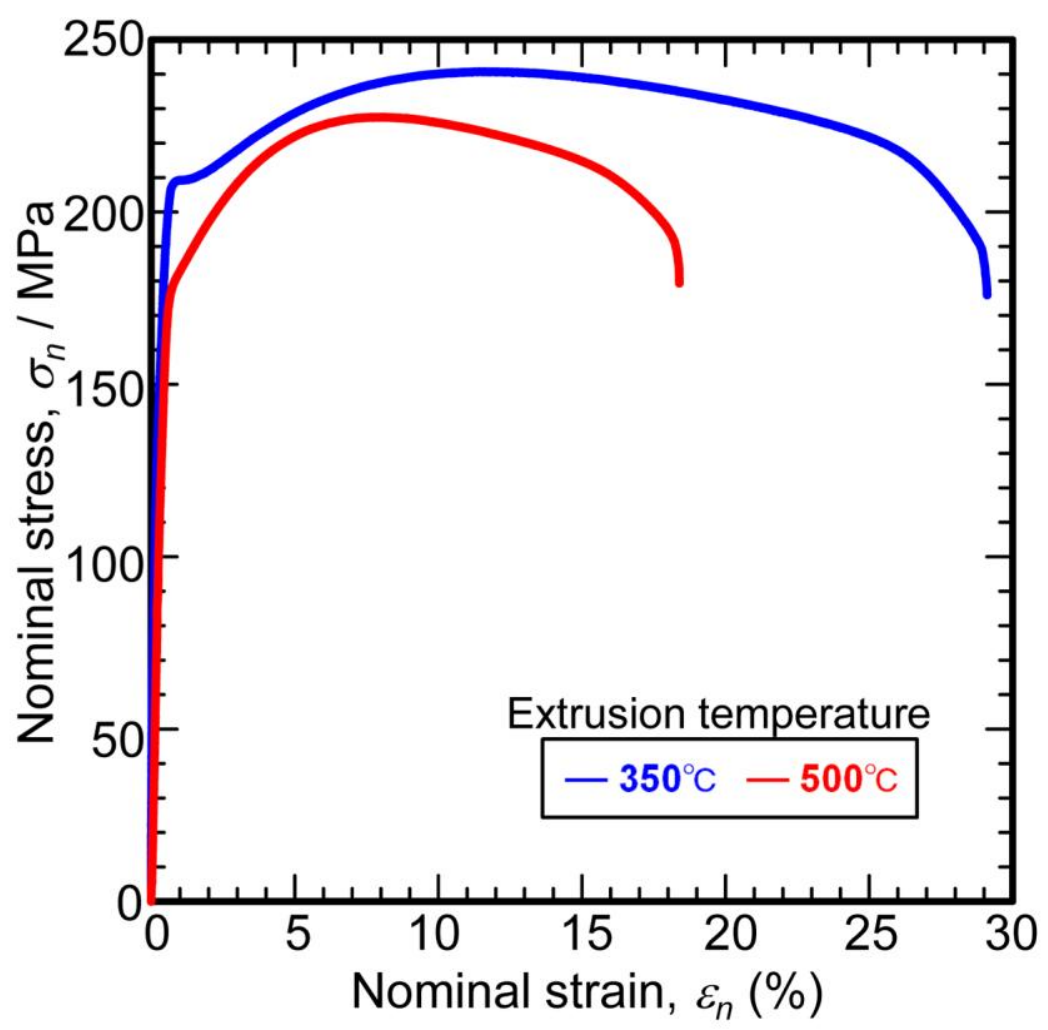


Table 1 Related microstructural factors for $\Delta \sigma_{\text {TPS }}$ and resulting $\Delta \sigma_{\text {TPS }}$ for the alloy samples extruded at $350{ }^{\circ} \mathrm{C}$ and $500{ }^{\circ} \mathrm{C}$

\begin{tabular}{ccccccc}
\hline $\mathrm{T}_{\text {ext }}\left[{ }^{\circ} \mathrm{C}\right]$ & $\mathrm{M}$ & $\mathrm{d}_{\mathrm{p}}[\mathrm{nm}]$ & $\mathrm{N}_{\mathrm{v}}\left[\mathrm{m}^{-3}\right]$ & $\mathrm{V}_{\mathrm{f}}[\%]$ & $\lambda[\mathrm{nm}]$ & $\Delta \sigma \mathrm{TPS}[\mathrm{MPa}]$ \\
\hline 350 & 4.4 & 15 & $4.9 \times 10^{20}$ & 0.089 & 554 & 28 \\
500 & 5.3 & 39 & $8.5 \times 10^{19}$ & 0.26 & 829 & 28 \\
\hline
\end{tabular}




\section{Figure Captions}

Figure 1: SEM image and EDS elemental mapping of as-cast $\mathrm{Mg}-0.27 \mathrm{Al}-0.13 \mathrm{Ca}-0.21 \mathrm{Mn}$ alloy sample as a billet for extrusion

Figure 2: (a) Bar surfaces of $\mathrm{Mg}-0.27 \mathrm{Al}-0.13 \mathrm{Ca}-0.21 \mathrm{Mn}$ alloy samples extruded at $350{ }^{\circ} \mathrm{C}$ and $500{ }^{\circ} \mathrm{C}$, (b) Extrusion limit diagram for comparison with commercial AZ31 alloy sample and high-speed extrudable $6063 \mathrm{Al}$ alloy sample, (c) Bar surfaces of AZ31 alloy samples extruded at $400{ }^{\circ} \mathrm{C}$ and a die-exit speed of $24 \mathrm{~m} / \mathrm{min}$ and $60 \mathrm{~m} / \mathrm{min}$

Figure 3: (a) Inverse pole figure (IPF) maps and (0001) pole figures on central sections parallel to extrusion direction of $\mathrm{Mg}-0.27 \mathrm{Al}-0.13 \mathrm{Ca}-0.21 \mathrm{Mn}$ alloy samples extruded at different temperatures, (b) Effect of extrusion temperature on grain size, Schmid factor for basal slip, and shear factor for tensile twinning of as-extruded alloy samples

Figure 4: $\mathrm{OM}$ images at positions of $5 \mathrm{~mm}, 10 \mathrm{~mm}$, and $12.5 \mathrm{~mm}$ in front of die-entrance of $\mathrm{Mg}-0.27 \mathrm{Al}-0.13 \mathrm{Ca}-0.21 \mathrm{Mn}$ alloy sample partially extruded at (a) $350{ }^{\circ} \mathrm{C}$ and (b) $500{ }^{\circ} \mathrm{C}$ Figure 5: IPF maps at positions of $10 \mathrm{~mm}$ and $12.5 \mathrm{~mm}$ in front of die-entrance of Mg-0.27Al-0.13Ca-0.21Mn alloy sample partially extruded at (a) $350{ }^{\circ} \mathrm{C}$ and (b) $500{ }^{\circ} \mathrm{C}$

Figure 6: (a) STEM image and STEM-EDS elemental mapping of Mg-0.27Al-0.13Ca-0.21Mn alloy sample extruded at $400{ }^{\circ} \mathrm{C}$, (b) STEM images of Mg-0.27Al-0.13Ca-0.21Mn alloy samples extruded at $350{ }^{\circ} \mathrm{C}$ and $500{ }^{\circ} \mathrm{C}$ 
Figure 7: (a) Tensile stress-strain curves of $\mathrm{Mg}-0.27 \mathrm{Al}-0.13 \mathrm{Ca}-0.21 \mathrm{Mn}$ alloy samples extruded at different temperatures, (b) Tensile proof stresses and tensile ductilities of Mg-0.27Al-0.13Ca-0.21Mn alloy samples extruded at $60 \mathrm{~m} / \mathrm{min}$, AZ31 alloy samples extruded at $2.5 \mathrm{~m} / \mathrm{min}$ and $20 \mathrm{~m} / \mathrm{min}$, dilute AZ alloy samples extruded at $30 \mathrm{~m} / \mathrm{min}$, and high-speed extrudable 6xxx Al alloy samples, (c) Compressive stress-strain curves of Mg-0.27Al-0.13Ca-0.21Mn alloy samples extruded at different temperatures

Figure 8: (a) Tensile and compressive proof stresses versus grain sizes of Mg-0.27Al-0.13Ca-0.21Mn alloy samples extruded at different temperatures, (b) Yield anisotropies versus grain sizes of $\mathrm{Mg}-0.27 \mathrm{Al}-0.13 \mathrm{Ca}-0.21 \mathrm{Mn}$ alloy samples extruded at different temperatures 
Figure 1

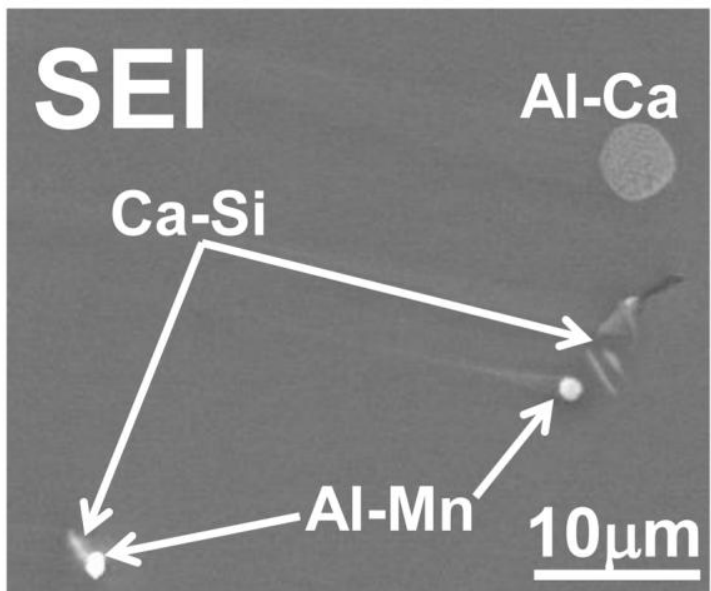

Mg

Al

$\mathrm{Ca}$

8

Mn

Si

$v$ 
Figure 2
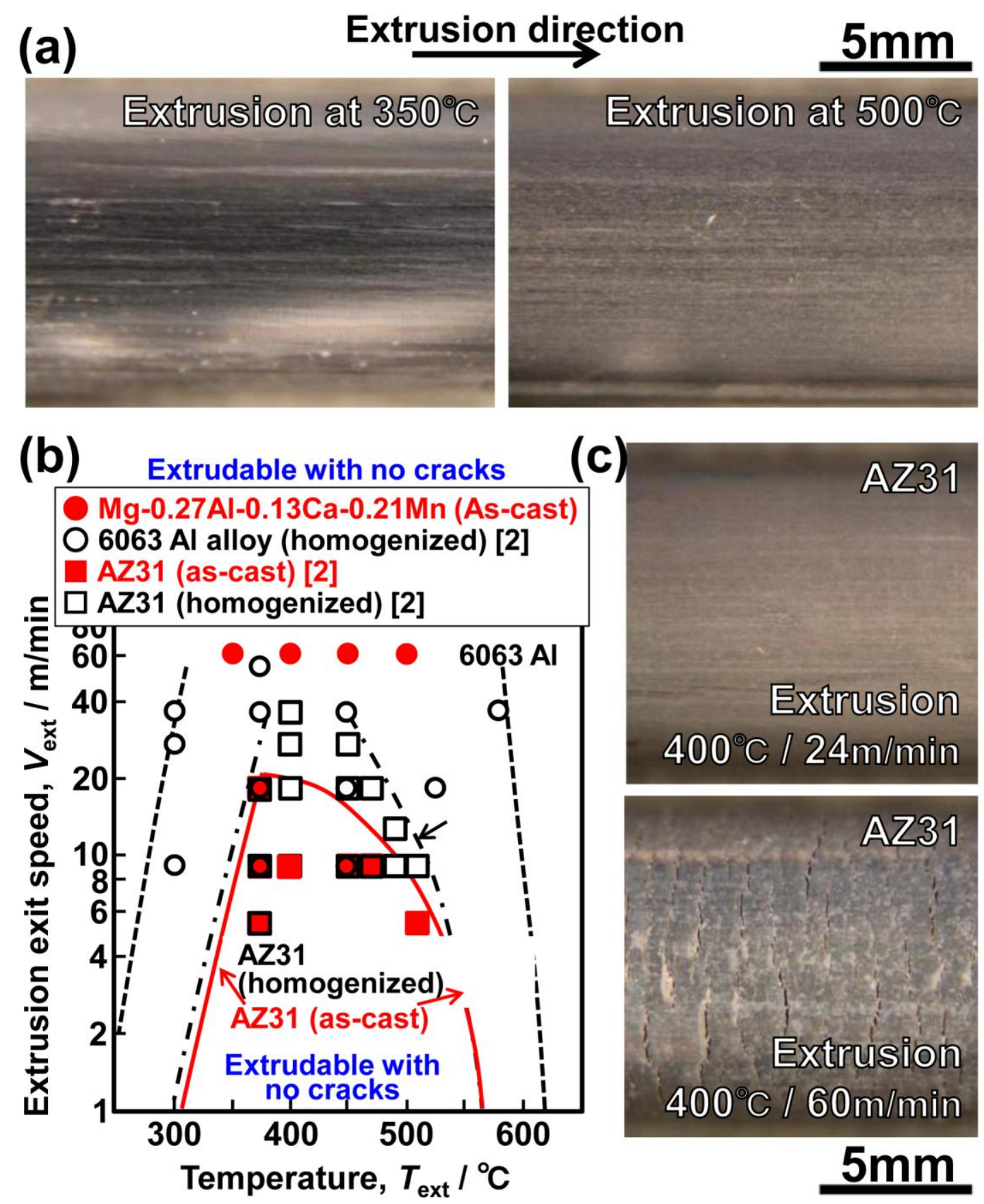
Figure 3

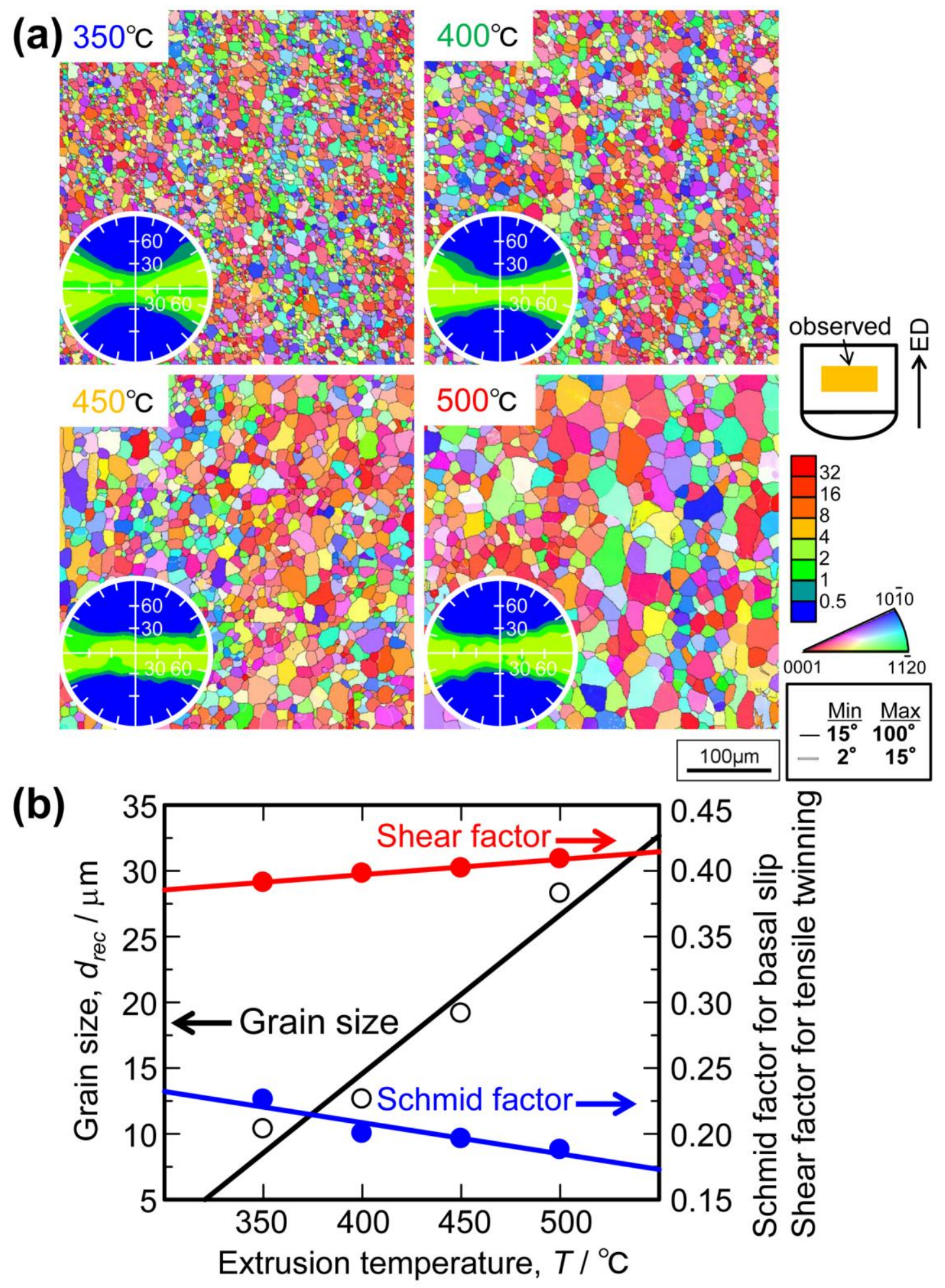


Figure 4

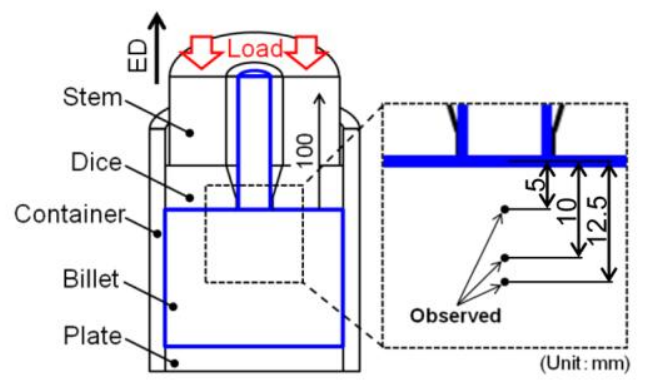

(a) Extrusion at $350^{\circ} \mathrm{C}$
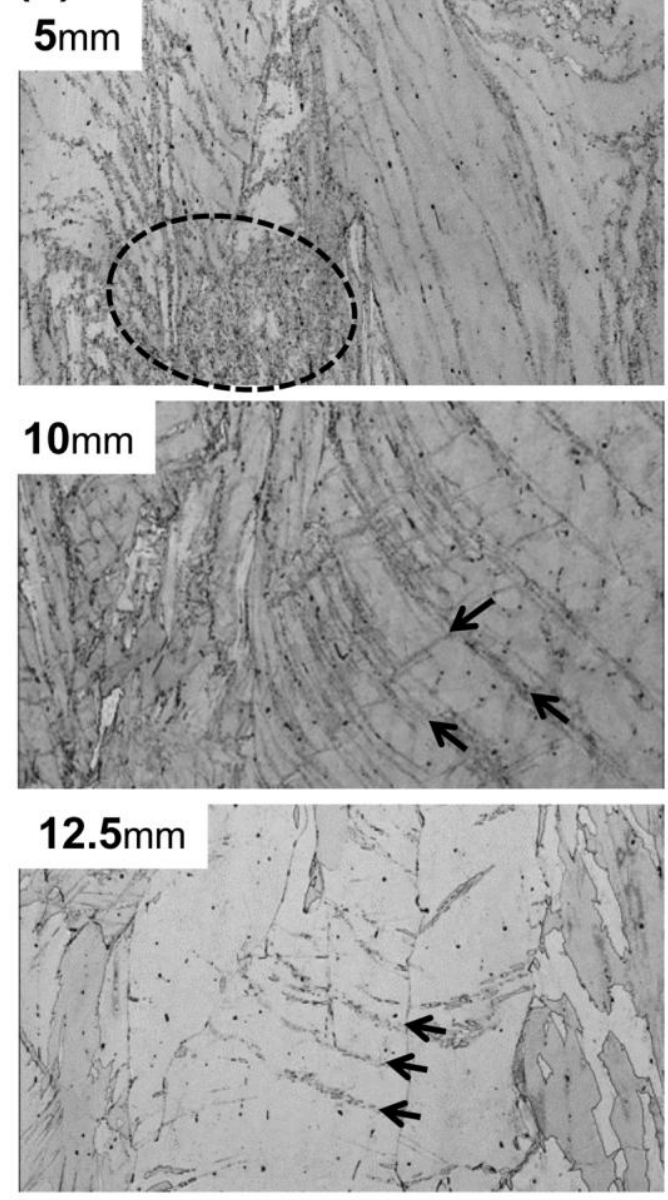

(b) Extrusion at $500^{\circ} \mathrm{C}$
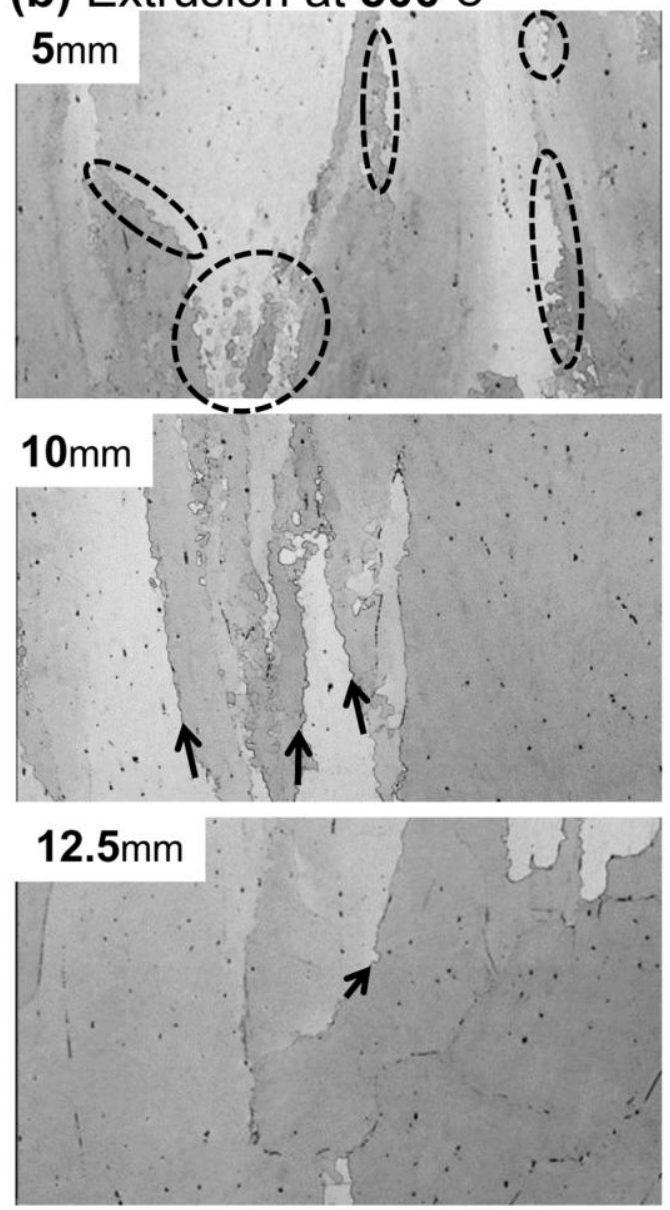

$500 \mu \mathrm{m}$ 
Figure 5

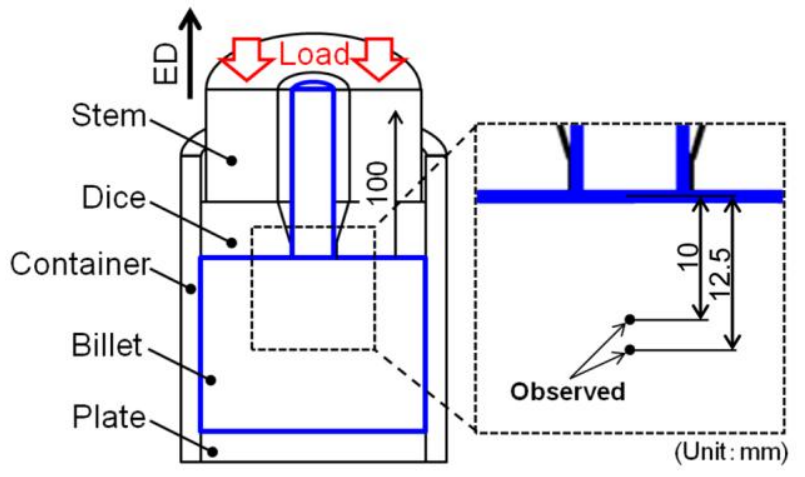

(a) Extrusion at $350^{\circ} \mathrm{C}$

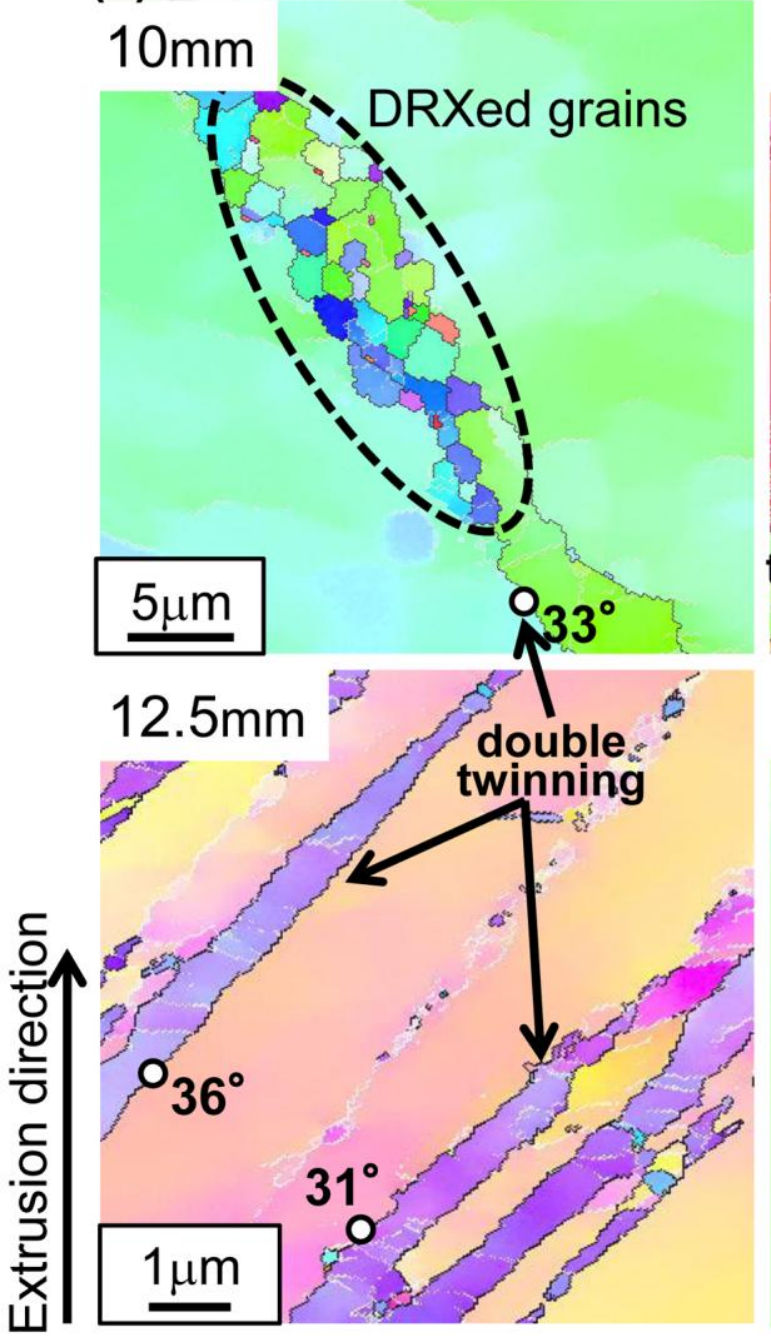

(b) Extrusion at $500^{\circ} \mathrm{C}$
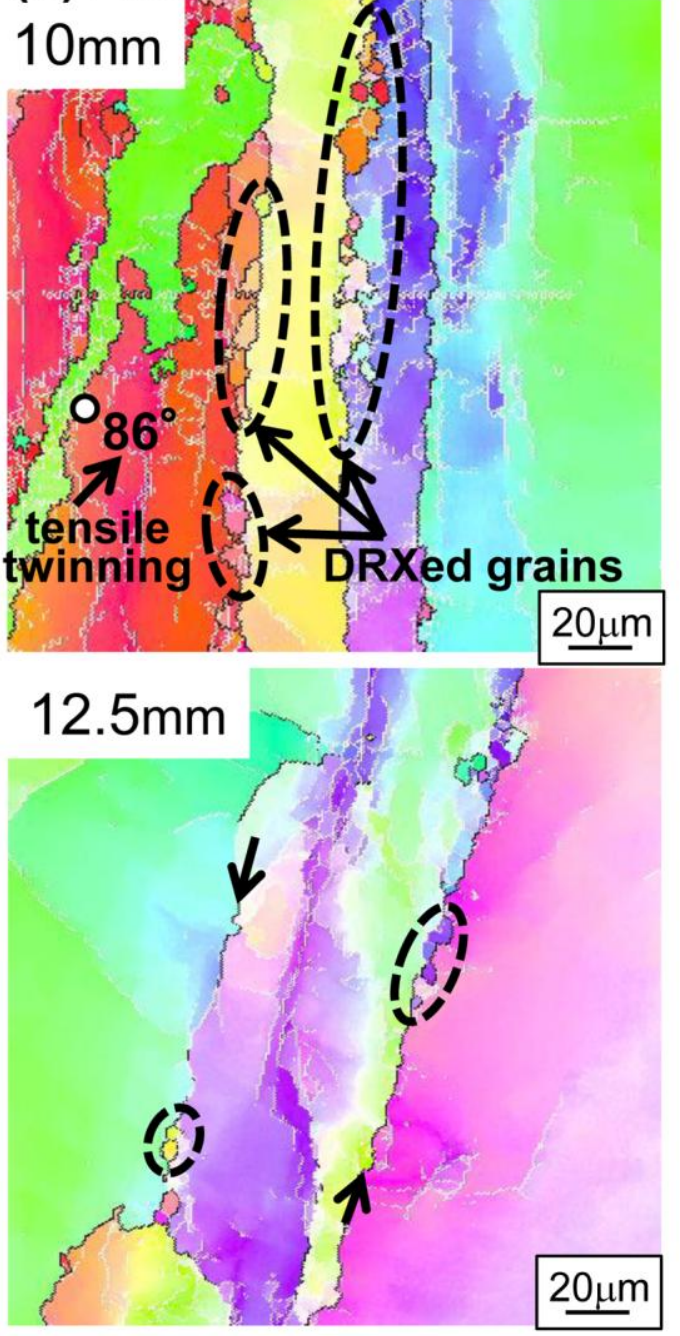
Figure 6

(a) Extrusion at $400^{\circ} \mathrm{C}$
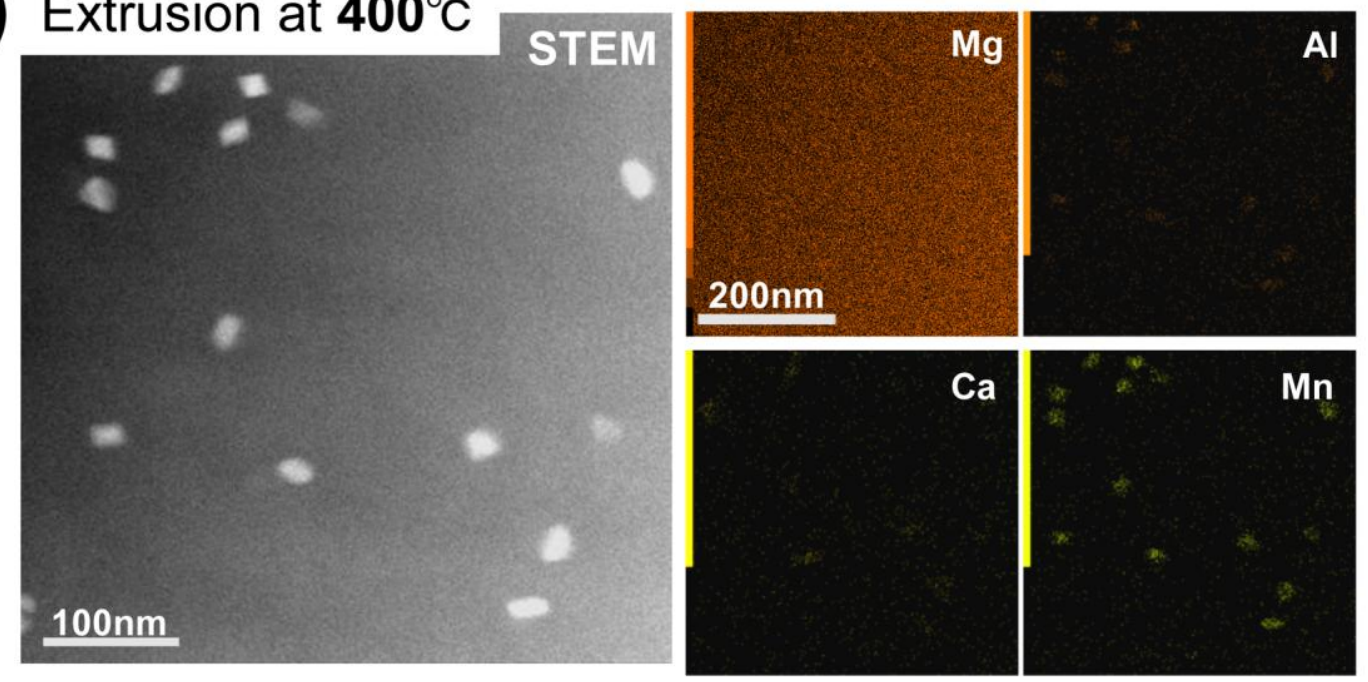

(b) Extrusion at $350^{\circ} \mathrm{C}$

Extrusion at $500^{\circ} \mathrm{C}$
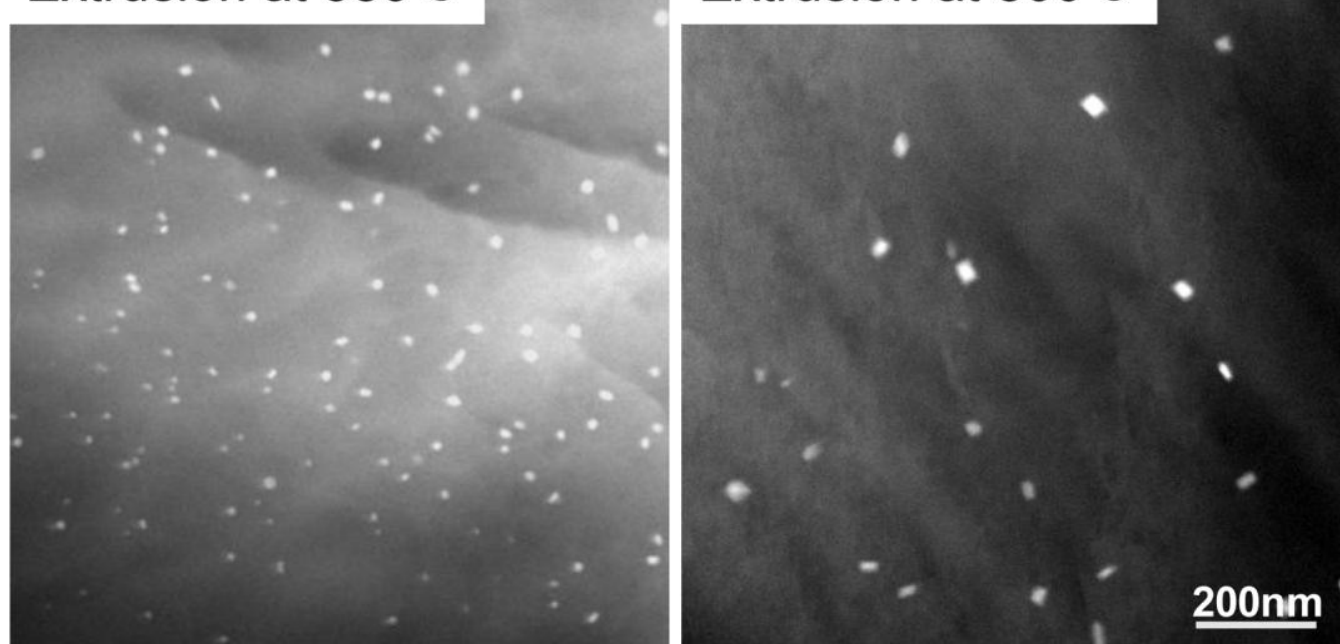
Figure 7
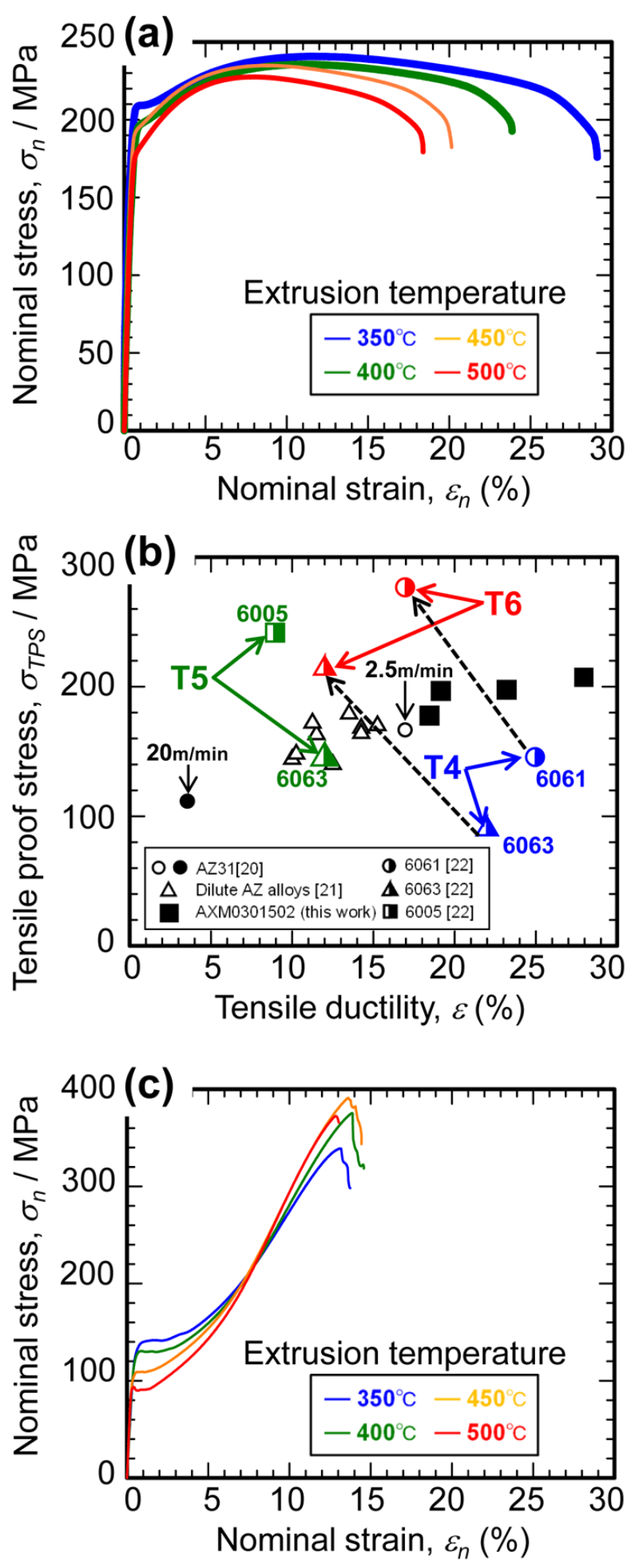
Figure 8
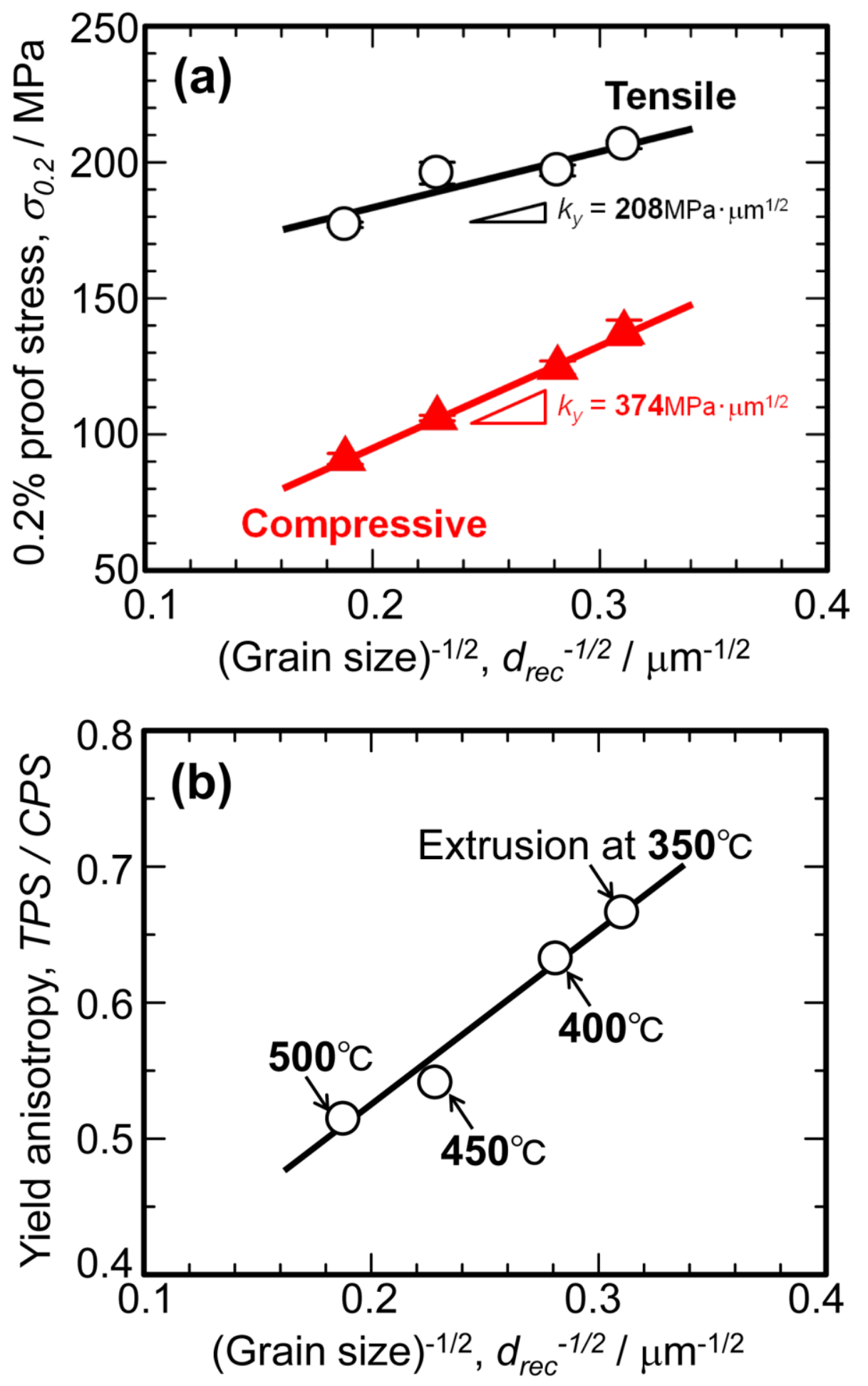